\title{
Evolution of $\alpha_{2}$-macroglobulin
}

\author{
The structure of a protein homologous with human $\alpha_{2}$-macroglobulin from plaice (Pleuronectes platessa $\mathbf{L}$.) \\ plasma
}

\author{
Phyllis M. STARKEY* and Alan J. BARRETT \\ Department of Biochemistry, Strangeways Laboratory, Worts Causeway, Cambridge CB1 4RN, U.K.
}

(Received 2 November 1981/Accepted 29 March 1982)

\begin{abstract}
The plaice (Pleuronectes platessa L.) papain-binding protein previously demonstrated to be homologous with human $\alpha_{2}$-macroglobulin, and designated plaice $\alpha_{2}$-macroglobulin homologue or $\alpha \mathrm{Mh}$, was shown to be a glycoprotein of $s_{20, w} 11.86 \mathrm{~S}$. In polyacrylamide-gel pore-limit electrophoresis under non-denaturing conditions plaice $\alpha \mathrm{Mh}$ migrated to the same position as half-molecules of human $\alpha_{2}$-macroglobulin, and treatment with methylamine or a proteinase caused no change in its electrophoretic properties. Either denaturation in urea $(4 \mathrm{M})$ or mild reduction by dithiothreitol $(1 \mathrm{mM})$ partially dissociated plaice $\alpha \mathrm{Mh}$ into half-molecules. Denaturation with reduction füther dissociated the protein into quarter-subunits. In sodium dodecyl sulphate/ polyacrylamide-gel electrophoresis under reducing conditions plaice $\alpha \mathrm{Mh}$ dissociated into subunits of $M_{\mathrm{r}} 105000$ (I) and 90000 (II). Approximately equal amounts of each subunit were formed, and peptide 'mapping' showed subunits I and II to be distinct polypeptide chains. Under alkaline denaturing conditions, a proportion of the I chains of aMh were cleaved into fragments of $M_{\mathrm{r}}$ about 60000 and 40000 . This cleavage was favoured by reducing conditions and prevented by prior inactivation of the $\alpha \mathrm{Mh}$ with methylamine. $\left[{ }^{14} \mathrm{C}\right]$ Methylamine allowed to react with $\alpha \mathrm{Mh}$ became covalently linked to subunit I. These properties suggested the existence of an autolytic site on subunit I analogous to the autolytic site of human $\alpha_{2}$-macroglobulin. Reaction of $\alpha \mathrm{Mh}$ with a proteinase resulted in cleavage of a fragment of $M_{\mathrm{r}} 10000-15000$ from subunit I. A proportion of the proteinase molecules trapped by $\alpha \mathrm{Mh}$ became covalently linked to the inhibitor. A scheme is proposed for the evolution of human $\alpha_{2}$-macroglobulin and plaice $\alpha \mathrm{Mh}$ from a common ancestral protein, which may also have been an ancestor of cornplement components $\mathrm{C} 3$ and $\mathrm{C} 4$.
\end{abstract}

The preceding papers (Starkey \& Barrett, 1982; Starkey et al., 1982) have demonstrated that a variety of animal species comprising mammals, birds, repiles and amphibians possess a papainbinding plasma protein similar to human $\alpha_{2}$-macroglobulin and of the same $M_{\mathrm{r}}(725000)$, whereas all fish species tested, including representatives of the dipnoans, actinopterygians, elasmobranchs and

\footnotetext{
Abbreviations used: $\alpha_{2} \mathrm{M}, \alpha_{2}$-macroglobulin; $\alpha \mathrm{Mh}$, $\alpha$-macroglobulin homologue; Dip-F, di-isopropyl phosphorofluoridate; Z-Arg-NNapOMe, benzyloxycarbonylL-arginine 2-(4-methoxy)naphthylamide; SDS, sodium dodecyl sulphate.

* Present address: Sir William Dunn School of Pathology, University of Oxford, South Parks Road, Oxford OX1 3RE, U.K.
}

cyclostomes, have a papain-binding protein of $M_{\mathrm{r}}$ 360000. Despite its lower $M_{\mathrm{r}}$, however, the papainbinding protein of plaice (Pleuronectes platessa $\mathrm{L}$.) plasma was shown to share so many of the distinctive inhibitory properties of human $\alpha_{2} \mathrm{M}$ that it must be considered homologous with the larger human protein.

Human $\alpha_{2} \mathbf{M}$ is a glycoprotein consisting of four identical polypeptide chains, $M_{\mathrm{r}} 182000$ (Barrett $e t$ al., 1974). The quarter-subunits are linked in pairs by disulphide bonds, and the half-molecules associate by non-covalent interactions. Native $\alpha_{2}$ M exists in two molecular conformations differing in their mobilities in polyacrylamide-gel electrophoresis and known as S ('slow')- and F ('fast')- $\alpha_{2} M$. Only S- $\alpha_{2} M$ binds and inhibits proteinases (Barrett et al., 1979). 
Reaction of S- $\alpha_{2} \mathrm{M}$ with a proteinase is initiated by proteolytic attack of the enzyme on a particular region in the middle of the quarter-subunit polypeptide chain known as the 'bait' region (Barrett et al., 1974). As a result of this cleavage, $\alpha_{2} M$ changes conformation from the $\mathrm{S}$ - to the $\mathrm{F}$-form, and the enzyme is physically trapped within the macroglobulin molecule. The bound enzyme retains its catalytic activity, though access of substrates, inhibitors and antibodies to the proteinase is sterically hindered (Barrett \& Starkey, 1973; Starkey \& Barrett, 1977).

When $S-\alpha_{2} \mathbf{M}$ is incubated in denaturing conditions a certain proportion of the quarter-subunits undergo cleavage at a point one-third of the way from the $C$-terminus. The proportion cleaved increases as the temperature and/or the $\mathrm{pH}$ increases, but is decreased by prior reduction of the $\alpha_{2} \mathrm{M}$. F- $\alpha_{2} \mathrm{M}$ is not cleaved. The cleavage is not due to contaminating proteinases, but is a property of the $\alpha_{2} M$ itself, and has been described as 'autolytic cleavage' (Barrett $e t$ al., 1979; Harpel et al., 1979; Howard et al., 1980; Sim \& Sim, 1981). It is now believed that the susceptible bond is adjacent to a glutamic acid residue that forms a thiol ester with a nearby cysteine residue. A chemical mechanism for the autolytic cleavage of the peptide bond has been proposed (Salvesen et al., 1981). In the unchanged $\alpha_{2} \mathbf{M}$ the thiol ester is protected within the molecule, but on conversion into $F-\alpha_{2} M$ or denaturation it becomes exposed and reacts with any nucleophilic species present. When $S-\alpha_{2} M$ reacts with a proteinase, a proportion of the trapped enzyme molecules become covalently linked to the $\alpha_{2} M$ through reaction of a lysine side chain with the autolytic site. The proportion of proteinase molecules covalently bound varies between enzymes, but covalent binding is not essential to the trapping and inhibition of proteinases by $\alpha_{2} \mathbf{M}$, and can be inhibited by competing low-molecular-weight nucleophiles without affecting the trapping and inhibition of proteinases by the macroglobulin. Methylamine is able to react with the thiol ester in unchanged S- $\alpha_{2} M$ and in so doing becomes covalently attached to the glutamic acid residue, preventing subsequent autolytic cleavage (Swenson \& Howard, 1979; Howard et al., 1980; Salvesen \& Barrett, 1980; Salvesen et al., 1981).

In the present paper we have studied the structure of the plaice $\alpha_{2}$-macroglobulin homologue $(\alpha M h)$ in the hope of increasing our knowledge of the mechanism of action of human $\alpha_{2} \mathbf{M}$ and providing some insight into its evolution.

\section{Materials and methods \\ Materials}

Sources of chemicals, and methods in addition to those mentioned in the preceding papers (Starkey \&
Barrett, 1982; Starkey et al., 1982), were as follows: Staphylococcus aureus V8 proteinase was from Miles Laboratories; Iodogen (1,3,4,6-tetrachloro3a,6 $\alpha$-diphenylglycoluril) was from Pierce and Warriner, Chester, Cheshire, U.K., and $\mathrm{Na}^{125} \mathrm{I}$ (essentially carrier-free) and $\left[{ }^{14} \mathrm{C}\right]$ methylamine were from The Radiochemical Centre. Plaice $\alpha \mathrm{Mh}$, unless otherwise stated, was in $0.1 \mathrm{M}$-sodium citrate buffer, pH6.5, containing $10 \%(\mathrm{v} / \mathrm{v})$ glycerol, and was inactivated with methylamine by incubation at $5 \mathrm{mg} / \mathrm{ml}$ (in citrate buffer adjusted to $\mathrm{pH} 8.0$ by the addition of $0.1 \mathrm{M}$-Tris/ $\mathrm{HCl}$ buffer, $\mathrm{pH} 9.0$ ) with $0.2 \mathrm{M}$-methylamine for $2 \mathrm{~h}$.

\section{Carbohydrate analyses}

Carbohydrate analyses were kindly performed by Professor J. Clamp, Department of Medicine, University of Bristol, Bristol, U.K., as described by Clamp (1977).

\section{Sedimentation-velocity ultracentrifugation}

Sedimentation-velocity ultracentrifugation of $\alpha \mathrm{Mh}$ $(4.3 \mathrm{mg} / \mathrm{ml})$ was kindly done by $\mathrm{Mr}$. Neville Buttress, A.R.C. Institute of Animal Physiology, Babraham, Cambridge, U.K. in a Beckman model E analytical ultracentrifuge:

\section{Radiochemical methods}

Pancreatic elastase was labelled with ${ }^{125} \mathrm{I}$ by the Iodogen method of Fraker \& Speck (1978) as modified by Salvesen et al. (1981). Radioactivities of samples were counted in a Packard BPGD Autogamma counter.

\section{Gel electrophoresis}

Conditions for SDS/polyacrylamide-slab-gel electrophoresis were as described by Barrett et al. (1979), except that samples were as a routine incubated for $30 \mathrm{~min}$ at $37^{\circ} \mathrm{C}$.

Peptide 'mapping' in polyacrylamide gels ( $15 \%$ total, $2.6 \%$ cross-linked) of $\alpha \mathrm{Mh}$ subunits subjected to limited proteolysis with Staphylococcus aureus V8 proteinase was as described by Salvesen \& Barrett (1980).

Gels were stained for glycoprotein by the method of Zacharius et al. (1969). Densitometry of stained gels was as described by Salvesen \& Barrett (1980). For radioautography, polyacrylamide gels dried on to filter paper (Whatman 3MM) were exposed to Fuji Rx-medical X-ray film for 4-7 days. The film was developed with Kodak DX-80 developer in accordance with the manufacturer's instructions. In all Figures of electrophoresis gels, migration was downwards, towards the anode.

\section{Results and discussion \\ Physical properties of plaice $\alpha \mathrm{Mh}$}

Carbohydrate content. Plaice $\alpha \mathrm{Mh}$ was shown to be a glycoprotein by its positive reaction in the 
periodic acid-Schiff procedure after polyacrylamide-gel electrophoresis under non-denaturing conditions. Carbohydrate analysis of the purified protein showed it to contain 54 residues of mannose, 40 residues of galactose, 5 residues of glucose, 49 residues of $N$-acetylglucosamine and 29 residues of sialic acid per molecule, taking an $M_{\mathrm{r}}$ for $\alpha \mathrm{Mh}$ of 390000 (see below). No lipid was detected.

Optical absorption coefficient. The protein concentrations of three separate preparations of $\alpha \mathrm{Mh}$ were determined by the method of Lowry et al. (1951) and the mean $A_{280}^{1 \%}$ was found to be 13.1.

Sedimentation coefficient. The major sedimenting species in the $\alpha \mathrm{Mh}$ preparation, which constituted more than $90 \%$ of the protein in the sample, had $s_{20, \mathrm{w}} 11.86 \mathrm{~S}$.

Polyacrylamide-gel pore-limit electrophoresis of $\alpha M h$ in non-denaturing conditions

$\alpha M h$ before and after treatment with a proteinase or methylamine. $\alpha \mathrm{Mh}(50 \mu \mathrm{g})$ was incubated under the conditions described previously for plasma (Starkey \& Barrett, 1982), with $0,2.5,5.0$ or $7.5 \mu \mathrm{g}$ of papain; $5 \mu \mathrm{g}$ of papain gave $100 \%$ saturation of the $\alpha \mathrm{Mh}$. The $\alpha \mathrm{Mh} /$ papain samples were analysed by polyacrylamide-gel pore-limit electrophoresis; the gel was then cut in half, and one half was stained for protein and the other for activity against Z-ArgNNapOMe. Acid-treated $\alpha_{2} M$ was included as a source of half-molecules of the human protein.

The results (Fig. 1) showed $\alpha \mathrm{Mh}$ to migrate to the

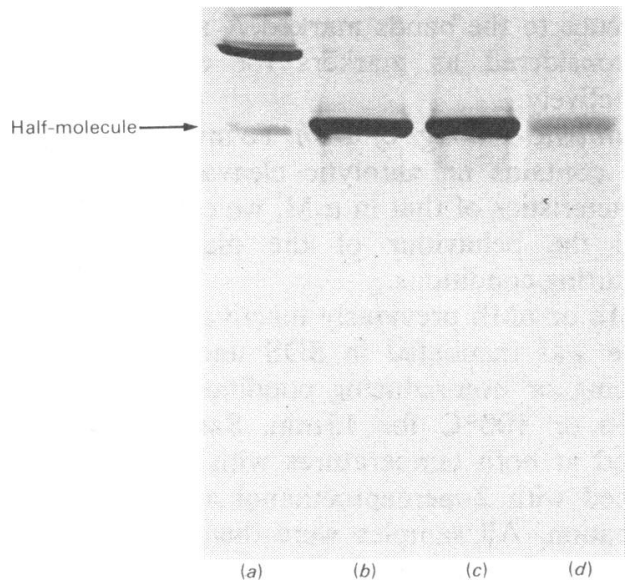

Fig. 1. Polyacrylamide-gel pore-limit electrophoresis of plaice $\alpha M h$

Samples were (a) acid-treated human $\alpha_{2} \mathbf{M},(b)$ plaice $\alpha \mathrm{Mh}(35 \mu \mathrm{g})$ and $(c$ and $d)$ plaice $\alpha \mathrm{Mh}(35 \mu \mathrm{g})$ preincubated with papain $(3.5 \mu \mathrm{g}) .(a)-(c)$ were stained for protein, and $(d)$ was stained for activity against Z-Arg-NNapOMe. The arrow indicates the position of the half-molecule of $\alpha_{2} \mathbf{M}$. same position as half-molecules of human $\alpha_{2} \mathrm{M}\left(M_{\mathrm{r}}\right.$ 360000 ). After reaction with papain, there was no evidence of a change in electrophoretic behaviour, and the band of activity staining coincided exactly with the single protein band, regardless of the amount of papain used.

Methylamine-inactivation of $\alpha \mathrm{Mh}$ also had no effect on its migration in this system.

aMh native or dissociated with urea and/or dithiothreitol. $\alpha \mathrm{Mh}$ in $50 \mathrm{mM}$-Tris/ $\mathrm{HCl}$ buffer, $\mathrm{pH} 8.0$, containing $10 \%(\mathrm{v} / \mathrm{v})$ glycerol was either incubated with $4 \mathrm{M}$-urea at $20^{\circ} \mathrm{C}$ for $4 \mathrm{~h}$, or reduced in $1 \mathrm{~mm}$-dithiothreitol for $30 \mathrm{~min}$ and free thiol groups then alkylated by addition of iodoacetic acid to a final concentration of $3 \mathrm{mM}$. A sample of the urea-denatured $\alpha \mathrm{Mh}$ was also reduced with dithiothreitol, and alkylated as above, and a sample of the reduced $\alpha \mathrm{Mh}$ was incubated with urea. $\alpha \mathrm{Mh}$ $(116 \mu \mathrm{g})$, both treated and untreated, was analysed by polyacrylamide-gel pore-limit electrophoresis.

Denaturation in $4 \mathrm{M}$-urea or reduction with $1 \mathrm{mM}$ dithiothreitol partially dissociated $\alpha \mathrm{Mh}$ into halfmolecules, whereas denaturation with reduction (the result was the same whether urea was added before or after the dithiothreitol) further dissociated $\alpha \mathrm{Mh}$ into quarter-subunits.

\section{Subunit structure of plaice $\alpha M h$}

Polyacrylamide-gel electrophoresis of $\alpha M h$ in denaturing conditions. Samples of plaice $\alpha \mathrm{Mh}$ denatured by incubation with SDS in either reducing or non-reducing conditions were analysed by polyacrylamide-gel electrophoresis. Human $\alpha_{2} \mathbf{M}$ lenatured but not reduced, and $\alpha_{2} \mathrm{M}$ incubated for $5 \mathrm{~min}$ with a less-than-saturating concentration of pancreatic elastase, inhibited with Dip-F and then denatured and reduced, were analysed at the same time for comparison.

As is shown in Fig. 2, human $\alpha_{2} \mathrm{M}$ denatured in non-reducing conditions gave a single band representing the dissociated half-molecules of $M_{\mathrm{r}} 360000$ (Barrett et al., 1979). Under denaturing and reducing conditions the $\alpha_{2} \mathrm{M} /$ elastase mixture gave some intact quarter-subunits, $M_{\mathrm{r}} 182000$, as well as the $111000-M_{\mathrm{r}}$ and $98000-M_{\mathrm{r}}$ fragments produced by the specific cleavage of the $\alpha_{2} M$ subunits in the 'bait' region.

Plaice $\alpha \mathrm{Mh}$ denatured without reduction gave a major band with a mobility slightly less than that of the $\alpha_{2} \mathrm{M}$ quarter-subunits. The sample also contained some high-molecular-weight material. Under denaturing and reducing conditions the plaice protein gave two major bands, designated I and II, of $M_{\mathrm{r}} 105000$ and 90000 respectively. A densitometer trace of such a gel indicated that band I consisted of two components, the minor component, designated Ia, having the lower mobility, and suggested that band II might also consist of two 


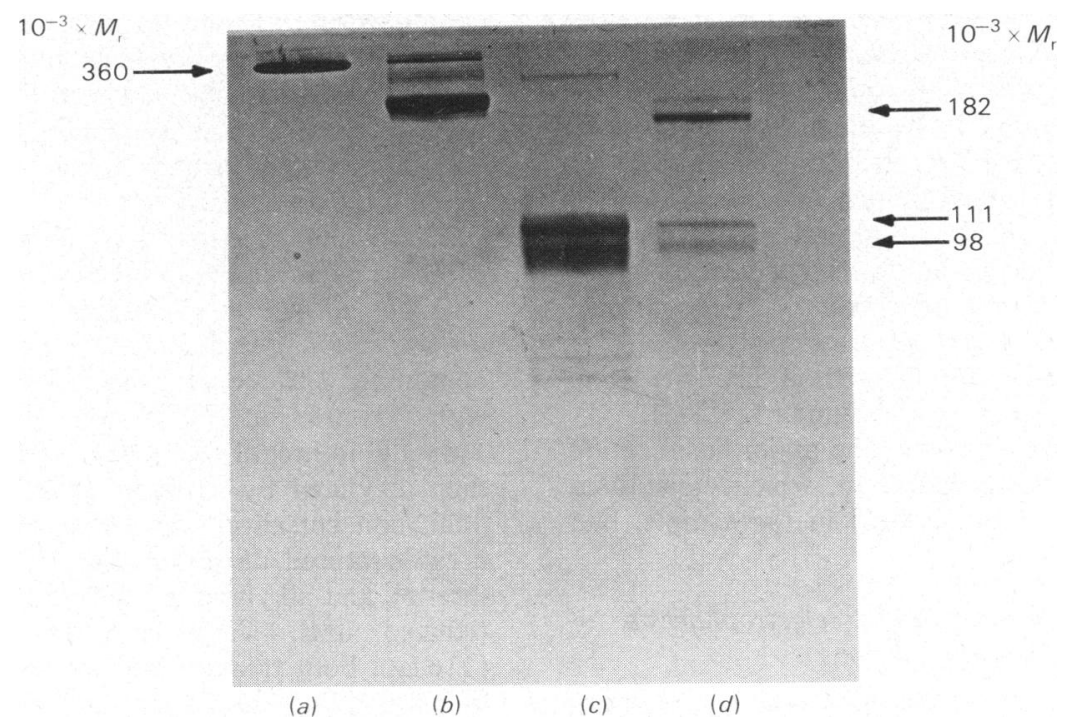

Fig. 2. SDS/polyacrylamide-gel electrophoresis of human $\alpha_{2} M$ and plaice $\alpha M h$

Samples were $(a)$ human $\alpha_{2} \mathrm{M}(10 \mu \mathrm{g})$ and $(b)$ plaice $\alpha \mathrm{Mh}(10 \mu \mathrm{g})$, both denatured without reduction, $(c)$ plaice $\alpha \mathrm{Mh}$ $(10 \mu \mathrm{g})$, and $(d)$ human $\alpha_{2} \mathrm{M}(10 \mu \mathrm{g})$ partially saturated with pancreatic elastase $(2 \mu \mathrm{g})$, both denatured and reduced. The $M_{\mathrm{r}}$ values of the $\alpha_{2} \mathrm{M}$ components are indicated.

components of slightly different $M_{\mathrm{r}}$. The $\alpha \mathrm{Mh}$ sample shown in Fig. 2 was isolated from pooled plasma, but similar patterns were obtained with preparations of $\alpha \mathrm{Mh}$ isolated separately from three different individual plasmas, indicating that the complexity of the pattern was not due to variation between individuals. Analysis of five different samples of $\alpha \mathrm{Mh}$ gave a ratio of bands I/II of 0.8-1.1:1.0. Band Ia comprised 26-29\% of band I, although because of the overlap between protein bands these values are only approximate. It thus appears that the plaice $\alpha \mathrm{Mh}$ molecule contains four polypeptide chains, two I chains and two II chains.

The amino acid sequences of the I and II chains were compared by peptide 'mapping' with Staphylococcus aureus V8 proteinase. $\alpha \mathrm{Mh}$ was subjected to electrophoresis under SDS/reducing conditions, slices of gel $(2 \mathrm{~mm}$ deep by the width of the sample lane) were cut from that region of the gel containing bands I and II and applied to the top of a second polyacrylamide gel (15\% total, $2.6 \%$ crosslinked) together with a sample of the Staphylococcus aureus V8 proteinase, and electrophoresed as described by Salvesen \& Barrett (1980).

The results (Fig. 3) indicate that bands I and II represent two different polypeptide chains, each with its own distinctive amino acid sequence. In order to have sufficient protein on the second-dimension gel, it was necessary to use a very high protein concentration on the first-dimension gel, so that inevitably the separation between bands I and II was incomplete. Nevertheless, it is clear that the upper gel sections, which contained mainly protein from band I, and the lower sections, which contained mainly band II protein, gave different 'mapping' patterns. This is particularly well illustrated with reference to the bands marked $A$ and $B$, which can be considered as markers for chains I and II respectively.

Autolytic cleavage of $\alpha M h$. To investigate whether $\alpha \mathrm{Mh}$ contains an autolytic cleavage site with the characteristics of that in $\alpha_{2} M$, we examined in more detail the behaviour of the plaice $\alpha \mathrm{Mh}$ under denaturing conditions.

$\alpha \mathrm{Mh}$ or $\alpha \mathrm{Mh}$ previously inactivated with methylamine was incubated in SDS under the standard reducing or non-reducing conditions, at $37^{\circ} \mathrm{C}$ for $30 \mathrm{~min}$ or $100^{\circ} \mathrm{C}$ for $15 \mathrm{~min}$. Samples were also treated at both temperatures with SDS alone, and reduced with 2-mercaptoethanol at the end of the incubation. All samples were then electrophoresed alongside mixtures of standard proteins.

Under non-reducing conditions at $37^{\circ} \mathrm{C}$ both the untreated (Fig. 4) and the methylamine-inactivated $\alpha \mathrm{Mh}$ (results not shown) gave a major product, designated band 1a, with a smaller amount of band 1b. At this high loading, several other minor bands were also visible. At $100^{\circ} \mathrm{C}$ the untreated $\alpha \mathrm{Mh}$ again gave $1 \mathrm{a}$ and $1 \mathrm{~b}$ as the major bands, with the relative amount of band $1 \mathrm{~b}$ being perhaps slightly less, but 


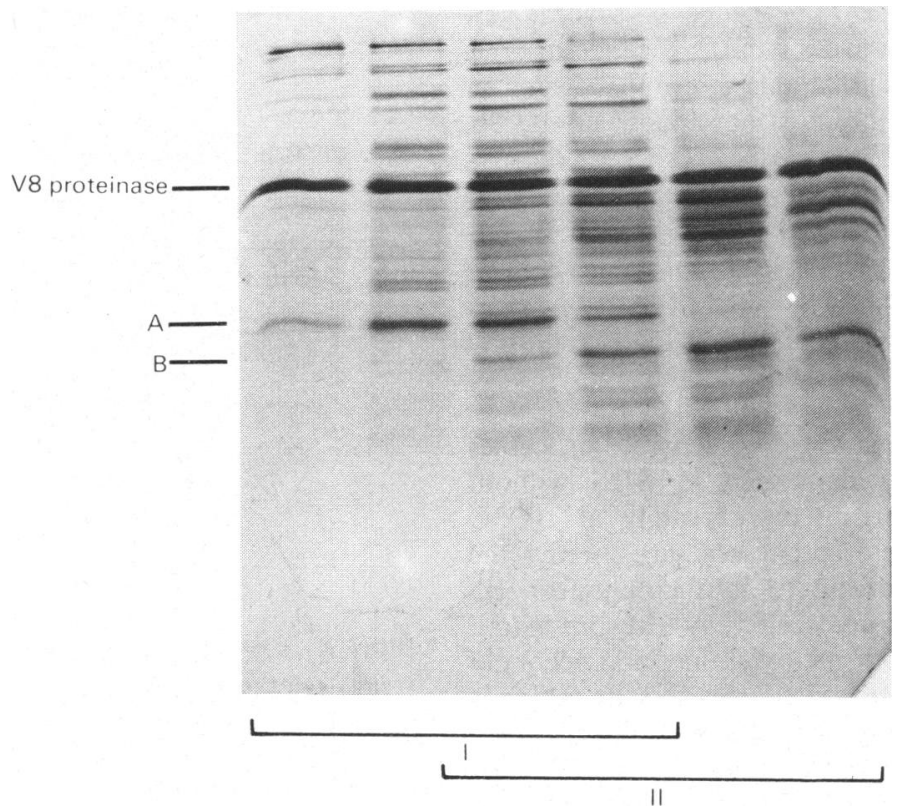

Fig. 3. Peptide 'mapping' of subunits I and II of plaice $\alpha M h$

$\alpha \mathrm{Mh}$ subunits I and II were partially separated by electrophoresis under SDS/reducing conditions. The respective gel sections were cut out, incubated with Staphylococcus aureus V8 proteinase and the peptide fragments run in a 'mapping' gel system. The brackets indicate the distribution of subunits I and II in the first-dimension gel.

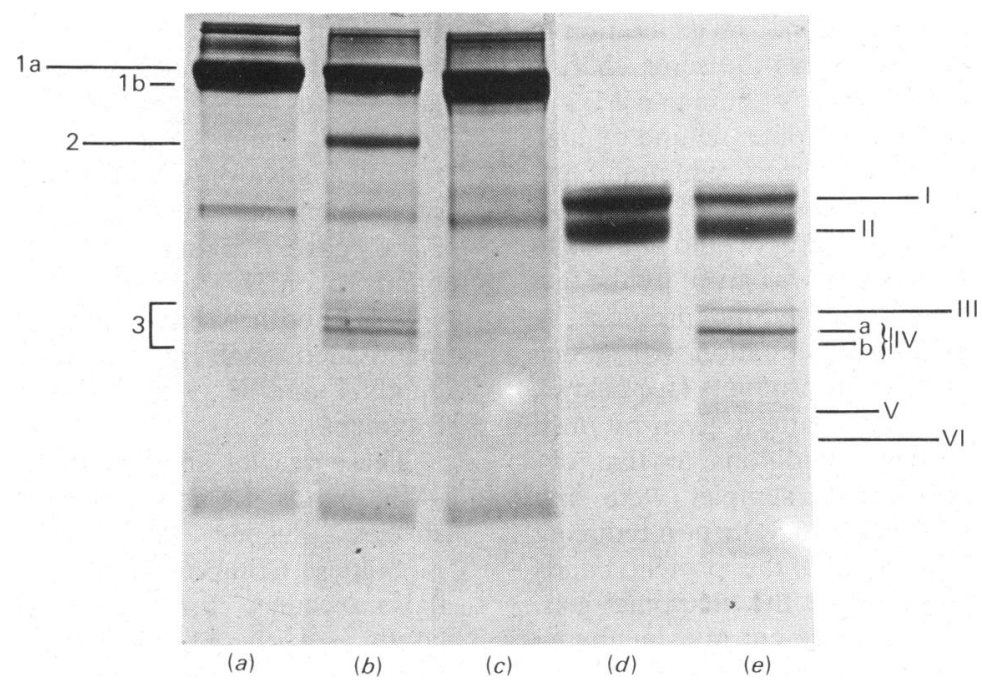

Fig. 4. Autolytic cleavage of plaice $\alpha \mathrm{Mh}$ under denaturing conditions

Samples $(a)-(c)$ were incubated under SDS/non-reducing conditions, $(d)$ and $(e)$ under SDS/reducing conditions. Samples were $(a) \alpha \mathrm{Mh}$ incubated at $37^{\circ} \mathrm{C}$ for $30 \mathrm{~min},(b)$ and $(e) \alpha \mathrm{Mh}$ incubated at $100^{\circ} \mathrm{C}$ for $15 \mathrm{~min},(c)$ methylamine-inactivated $\alpha \mathrm{Mh}$ incubated at $100^{\circ} \mathrm{C}$ for $15 \mathrm{~min}$, and $(d)$ methylamine-inactivated $\alpha \mathrm{Mh}$ incubated at $37^{\circ} \mathrm{C}$ for $30 \mathrm{~min}$.

Vol. 205 
more striking was the appearance of several new protein species. These were band 2, a single discrete fragment of $M_{\mathrm{r}} 132000$, and a group of smaller fragments, of which the most abundant, $3 a$ and $3 b$, had $M_{\mathrm{r}} 65000$ and 63000 respectively. In contrast, the methylamine-inactivated $\alpha \mathrm{Mh}$ heated at $100^{\circ} \mathrm{C}$ showed no evidence of fragments $2,3 a$ or $3 b$. At this higher temperature, however, the methylamineinactivated $\alpha \mathrm{Mh}$ gave an increased proportion of the lb component, compared either with the pattern given by the same $\alpha \mathrm{Mh}$ sample incubated at $37^{\circ} \mathrm{C}$ or with that of untreated $\alpha \mathrm{Mh}$ incubated at $100^{\circ} \mathrm{C}$.

These results suggest that two separate processes occur when $\alpha \mathrm{Mh}$ is denatured in SDS without reduction, both occurring more readily at $100^{\circ} \mathrm{C}$ than at $37^{\circ} \mathrm{C}$. These processes are firstly the conversion of component $1 \mathrm{a}$ into component $1 \mathrm{~b}$, which is apparently unaffected by the pre-inactivation of the $\alpha \mathrm{Mh}$ with methylamine, and secondly the formation of components $2,3 a$ and $3 b$, which is completely prevented by methylamine.

In reducing conditions all samples gave the major bands I and II, but $\alpha \mathrm{Mh}$ incubated at $100^{\circ} \mathrm{C}$ showed extra fragments that were present at only very low concentrations in $\alpha \mathrm{Mh}$ incubated at $37^{\circ} \mathrm{C}$. These were fragments III, IV, V and VI of $M_{\mathrm{r}} 63000$, 58000,43000 and 39000 respectively. At either $37^{\circ} \mathrm{C}$ or $100^{\circ} \mathrm{C}$ pre-inactivation of the $\alpha \mathrm{Mh}$ with methylamine prevented the generation of fragments III-VI, and at both temperatures $\alpha \mathrm{Mh}$ denatured by incubation with SDS alone, and reduced just before electrophoresis, generated higher concentrations of the fragments than did $\alpha \mathrm{Mh}$ reduced and denatured at the beginning of the incubation. The generation of fragments III-VI therefore shows the same characteristics as the autolytic cleavage of human $\alpha_{2} \mathrm{M}$ : it is favoured by denaturation at alkaline $\mathrm{pH}$ and by high temperature, disfavoured by prior reduction, and prevented by inactivation with methylamine. Further evidence that the cleavage is autolytic and not due to contamination with proteinases was given by the fact that cleavage was unaffected by the presence or absence of $1 \mathrm{mM}$-Dip-F, and incubation with added proteinases gave quite different products (see below).

In an attempt to relate the pattern given by $\alpha \mathrm{Mh}$ denatured in non-reducing conditions to that obtained in reducing conditions, samples were first prepared under the standard SDS/non-reducing conditions, electrophoresed and the protein bands detected by brief staining as for the 'mapping' gels. The desired sections of gel were cut out, incubated for $30 \mathrm{~min}$ at $20^{\circ} \mathrm{C}$ in upper-reservoir buffer $(1.1 \mathrm{ml})$ containing SDS and $10 \mathrm{~mm}$-dithiothreitol, and then placed in the sample slots of a fresh polyacrylamide gel and electrophoresed under denaturing conditions as usual.

The results obtained with $\alpha \mathrm{Mh}$ denatured without reduction at $100^{\circ} \mathrm{C}$ are shown in Fig. 5. In the

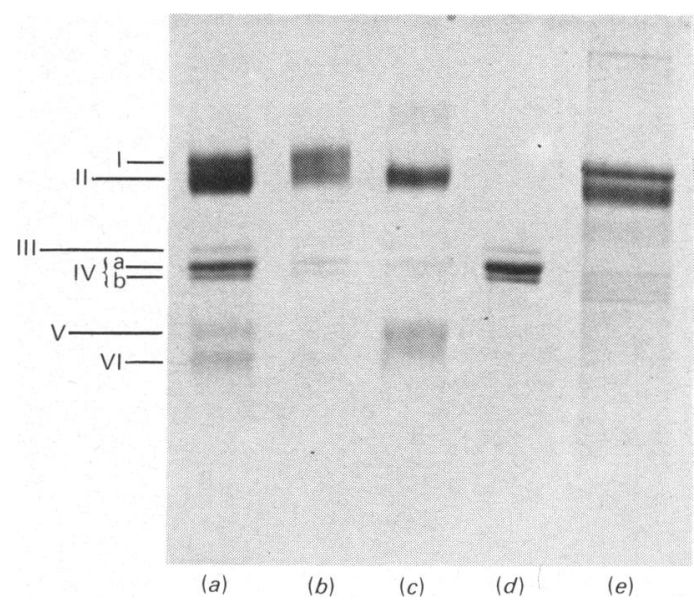

Fig. 5. SDS/polyacrylamide-gel electrophoresis in reducing conditions of components of $\alpha M h$ generated by denaturation without reduction

Samples had all been incubated in SDS/reducing conditions and were $(a)$ component $1 \mathrm{a},(b)$ component $1 \mathrm{~b},(c)$ component 2 and $(d)$ component 3 , all derived from $\alpha \mathrm{Mh}$ treated at $100^{\circ} \mathrm{C}$ for $15 \mathrm{~min}$ in SDS without reduction. (e) was $\alpha \mathrm{Mh}$ not pretreated.

second dimension, band 1a, when reduced, gave all the fragments normally seen with $\alpha \mathrm{Mh}$ denatured and reduced at $100^{\circ} \mathrm{C}$, i.e. bands I-VI, and band IV could now be seen to be a doublet. Band $1 \mathrm{~b}$ gave an almost identical pattern though fainter, presumably because band $1 \mathrm{~b}$ on the first-dimension gel had contained less protein than had band 1a. Band 2 gave bands II, V and VI only, with no detectable subunit I. Band 3 ( $3 a$ and $3 b$ having been cut out together) gave only bands III, IVa and IVb. Of the other samples, band $1 \mathrm{a}$ from $\alpha \mathrm{Mh}$ incubated at $37^{\circ} \mathrm{C}$ gave a pattern identical with that given by band $1 \mathrm{a}$ or $1 \mathrm{~b}$ from $\alpha \mathrm{Mh}$ incubated at $100^{\circ} \mathrm{C}$. In contrast, both bands $1 \mathrm{a}$ and $1 \mathrm{~b}$ from methylamineinactivated $\alpha \mathrm{Mh}$ incubated at $100^{\circ} \mathrm{C}$ gave only bands I and II, with no evidence of any smaller fragments.

These results show that, for a given sample of $\alpha \mathrm{Mh}$, bands $1 \mathrm{a}$ and $1 \mathrm{~b}$ contain the same protein species, despite their different electrophoretic mobilities. Components $1 \mathrm{a}$ and $1 \mathrm{~b}$ each represent half-molecules, I-II dimers linked by disulphide bonds (see Fig. 8), and both bands $1 \mathrm{a}$ and $1 \mathrm{~b}$ can consist of a mixture of intact and autolytically cleaved half-molecules. The difference between components $1 \mathrm{a}$ and $1 \mathrm{~b}$ is not due to denaturation to dissimilar half-molecules of I-I and II-II dimer or to autolytic cleavage, but to some other chemical change (loss of amides or carbohydrate, cleavage of disulphides?) at the higher temperature. 
Bands 2, 3a and 3b, on the other hand, are generated by autolytic cleavage, and the finding that band 2 comprised intact II chains linked by disulphide bonds to fragments $\mathrm{V}$ or VI strongly suggested that the autolytic cleavage site is located on subunit I, dividing the polypeptide chain into fragments of $M_{\mathrm{r}}$ about 40000 and 60000 , corresponding to fragments V or VI, and III or IV. More direct evidence for this hypothesis was sought by attempting to link $\left[{ }^{14} \mathrm{C}\right]$ methylamine covalently to $\alpha \mathrm{Mh}$

$\alpha \mathrm{Mh}(98 \mu \mathrm{g}$ in $40 \mu \mathrm{l})$ was incubated overnight at $20^{\circ} \mathrm{C}$ at $\mathrm{pH} 8.0$ with $15 \mu \mathrm{l}$ of $\left[{ }^{14} \mathrm{C}\right]$ methylamine $(25 \mathrm{mM}, 1 \mathrm{mCi} / \mathrm{ml})$ before being analysed by electrophoresis under SDS/reducing conditions.

The stained gel showed the usual pattern of protein bands for $\alpha \mathrm{Mh}$, and a radioautograph of the dried gel demonstrated a single band of radioactivity corresponding to subunit I; no radioactivity was associated with subunit II. It was concluded that $\alpha \mathrm{Mh}$ contains a site on subunit I that forms an SDS-stable (probably covalent) link with methylamine. Since such a covalent-linking site has previously been described only in human $\alpha_{2} \mathbf{M}$ and complement components $\mathrm{C} 3$ and $\mathrm{C} 4$ (Swenson \& Howard, 1979; Tack et al., 1980; Janatova \& Tack, 1981), where it is identical with the autolytic site, and since $\alpha \mathrm{Mh}$, in common with these proteins, is prevented from autolytic cleavage by reaction with methylamine, it seems almost certain that the methylamine covalent-linking site and the autolytic site of $\alpha \mathrm{Mh}$ are identical.

\section{Specific cleavage of aMh by a proteinase}

Since $\alpha \mathrm{Mh}$ binds only catalytically active proteinases (Starkey et al., 1982) it seemed likely that, as for $\alpha_{2} \mathbf{M}$, the interaction of the plaice protein with a proteinase was initiated by specific proteolytic cleavage of the inhibitor.

SDS/polyacrylamide-gel electrophoresis under reducing conditions of $\alpha \mathrm{Mh}$ before and after saturation with pancreatic elastase suggested that the enzyme might be cleaving a fragment from subunit I of the inhibitor, so altering its mobility to that of subunit II. To test this hypothesis, $\alpha \mathrm{Mh}$ was labelled specifically in subunit $I$ by overnight incubation with $\left[{ }^{14} \mathrm{C}\right]$ methylamine as described above. Portions of the $\left[{ }^{14} \mathrm{C}\right]$ methylamine/ $\alpha \mathrm{Mh}$ mixture were then incubated at $20^{\circ} \mathrm{C}$ for $10 \mathrm{~min}$ with saturating amounts of either pancreatic elastase or thermolysin (each $50 \mu \mathrm{g} / \mathrm{mg}$ of $\alpha \mathrm{Mh}$ ). The enzymes were then inhibited by $1 \mathrm{~mm}$-Dip-F or $10 \mathrm{~mm}$-EDTA and the mixtures were analysed by SDS/polyacrylamide-gel electrophoresis under reducing conditions. Control samples were as above but without the enzymes, or as above but with incubation of the enzymes with the appropriate inhibitor for $10 \mathrm{~min}$ before the addition of $\alpha \mathrm{Mh}$.
The results (Fig. 6) confirmed that with unchanged $\alpha \mathrm{Mh}$ the $\left[{ }^{14} \mathrm{C}\right]$ methylamine became covalently linked to subunit I. On reaction with saturating amounts of elastase or thermolysin the protein band due to subunit I became much fainter, and the radioautograph of the dried gel showed the major band of radioactivity in these samples to have an increased mobility comparable with that of subunit II; elastase gave a smaller increase in mobility than did thermolysin. Controls with inactivated enzymes gave the same pattern as the unchanged $\alpha \mathrm{Mh}$. It therefore appears that reaction of a proteinase with $\alpha \mathrm{Mh}$ involves proteolytic cleavage of subunit $I$ such that a fragment of $M_{\mathrm{r}}$ $10000-15000$ is cleaved from one end of the polypeptide chain. In this experiment the labelled aMh had of course been inactivated by its reaction with methylamine, but the fact that inactivated human $\alpha_{2} \mathbf{M}$ is still cleaved specifically by proteinases in the 'bait' region (Barrett et al., 1979), and that, with the exception of small amounts of additional low-molecular-weight fragments, methylamine-inactivated $\alpha \mathrm{Mh}$ and active $\alpha \mathrm{Mh}$ when incubated with proteinases both gave the same pattern of bands in SDS/polyacrylamide-gel electrophoresis, suggest that these results can be applied to the reaction of native $\alpha \mathrm{Mh}$ with a proteinase.

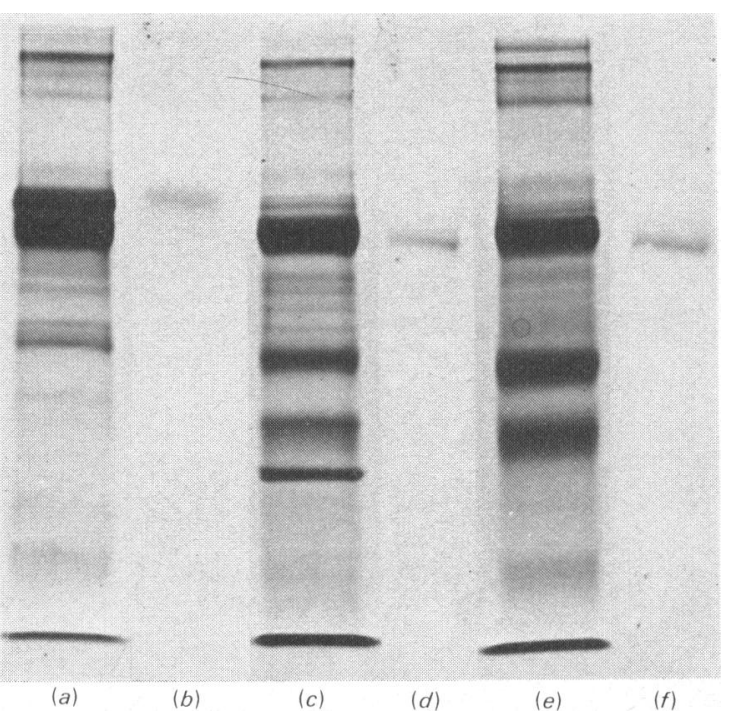

Fig. 6. SDS/polyacrylamide-gel electrophoresis of $\left[{ }^{14} \mathrm{C}\right]$ methylamine-labelled $\alpha M h$ with and without $a$ proteinase

Samples contained $\left[{ }^{14} \mathrm{C}\right]$ methylamine-labelled $\alpha \mathrm{Mh}$ $(16 \mu \mathrm{g})$ alone $(a$ and $b)$, with $2 \mu \mathrm{g}$ of thermolysin $(c$ and $d)$ or with $2 \mu \mathrm{g}$ of pancreatic elastase $(e$ and $f$ ). $(a),(c)$ and $(e)$ were stained for protein; $(b)(d)$ and $(f)$ are the corresponding radioautographs. 


\section{Covalent binding of the trapped proteinase to $\alpha M h$}

The ability of $\alpha \mathrm{Mh}$ to form a covalent link with some of the trapped proteinase molecules was investigated by incubating $\alpha \mathrm{Mh}(168 \mu \mathrm{g})$ with ${ }^{125} \mathrm{I}$ labelled elastase $(5 \mu \mathrm{g})$ at $20^{\circ} \mathrm{C}$ for $5 \mathrm{~min}$, inactivating the enzyme with $10 \mathrm{~mm}$-Dip-F for $30 \mathrm{~min}$, and then subjecting the mixture to electrophoresis under standard non-denaturing conditions in a $5 \%$ polyacrylamide gel. Protein bands were detected by brief staining, and the $\alpha \mathrm{Mh}$ band was cut out, rinsed in upper-reservoir buffer and incubated for $30 \mathrm{~min}$ at $37^{\circ} \mathrm{C}$ in $1 \mathrm{ml}$ of modified SDS/reducing sample buffer containing no glycerol. The gel section was then placed in a sample slot of a $7 \%$ polyacrylamide gel and run under standard SDS/reducing conditions simultaneously with a control sample of $\alpha \mathrm{Mh}$ incubated with Dip-F-inactivated ${ }^{125}$ I-labelled elastase.

The radioautograph of the stained gel (Fig. 7) showed that under denaturing and reducing conditions most of the radioactivity of the $\alpha \mathrm{Mh}-$

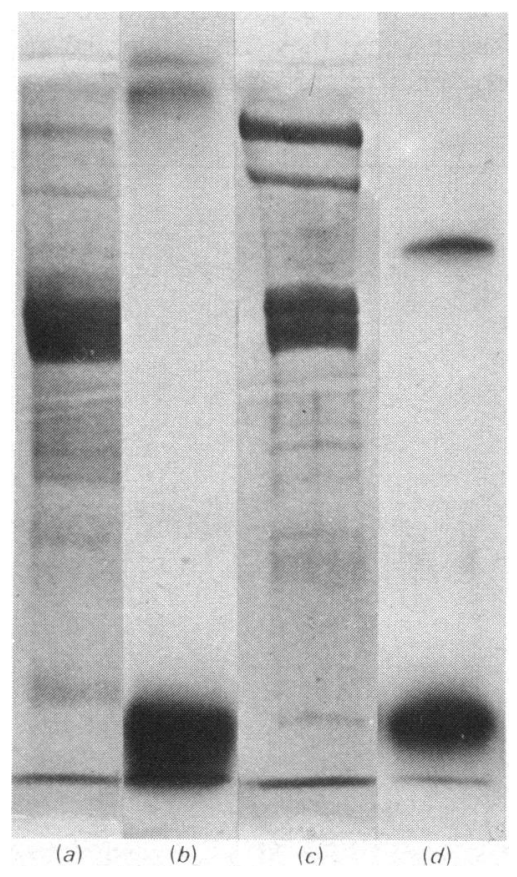

Fig. 7. SDS/polyacrylamide-gel electrophoresis of $\alpha M h-$ ${ }^{125}$ I-labelled elastase complex

Samples were $(a$ and $b)$ plaice $\alpha \mathrm{Mh}(13.7 \mu \mathrm{g})$ incubated with Dip-F-inactivated ${ }^{125}$ I-labelled elastase $(5 \mu \mathrm{g})$ and $(c$ and $d) \alpha \mathrm{Mh}-{ }^{125}$ I-labelled elastase complex, isolated electrophoretically as described in the text, from a mixture containing $50 \mu \mathrm{g}$ of $\alpha \mathrm{Mh} .(a)$ and $(c)$ were stained for protein; $(b)$ and $(d)$ are the corresponding radioautographs.
${ }^{125}$ I-labelled elastase complex ran just behind the dye front with the mobility of free enzyme. However, about $5 \%$ of the radioactivity (measured by counting the radioactivities of sections of the dried gel) was localized in a discrete band corresponding to a very faint protein band of mobility between that of the $\alpha \mathrm{Mh}$ subunits and that of $\alpha \mathrm{Mh}$ half-molecules. No such band was present in the $\alpha \mathrm{Mh} /$ inactivated elastase mixture, showing that its appearance was dependent on complex-formation. The band presumably represents enzyme covalently linked to the methylamine-binding autolytic site on subunit I. The fact that only a very small proportion of the enzyme trapped in the $\alpha \mathrm{Mh}$-elastase complex was covalently bound to the $\alpha \mathrm{Mh}, 95 \%$ being released from the complex by denaturation, shows that, as with $\alpha_{2} \mathrm{M}$, the covalent binding of the proteinase to the inhibitor is not essential for the trapping of enzyme by $\alpha \mathrm{Mh}$.

\section{Conclusions}

From the results obtained by gel electrophoresis of $\alpha \mathrm{Mh}$ in both non-denaturing and denaturing systems, we propose a model for the structure of the plaice protein that is depicted schematically in Fig. 8. In the native protein, subunits I and II are linked in heterologous dimers by disulphide bonds, and these dimers associate in pairs by non-covalent interactions. It has not been possible to determine whether reduction with dithiothreitol dissociates the molecule to a mixture of I-I and II-II dimers, or to I-II dimer only, and for this reason we have not specified whether the non-covalent interactions are between homologous or heterologous subunits.

The multiplicity of fragments generated by autolytic cleavage of subunit I under denaturing conditions is a little puzzling. One possibility is that there are two autolytic sites separated by about 20 amino acid residues, but this seems unlikely. A second, more plausible, explanation may be that different $\alpha \mathrm{Mh}$ molecules contain variable amounts of carbohydrate. Such heterogeneity would lead to multiple bands in SDS/polyacrylamide-gel electrophoresis, and may be responsible for the difference between subunits $1 \mathrm{a}$ and $1 \mathrm{~b}$. It should be noted that, with human $\alpha_{2} \mathrm{M}$, component III generated by autolytic cleavage also runs as a doublet (Barrett et al., 1979).

We have been unable to obtain direct evidence that $\alpha \mathrm{Mh}$ undergoes a conformational change; unlike $\alpha_{2} \mathrm{M}$ (Barrett et al., 1979), it exhibits no change in migration in polyacrylamide-gel pore-limit electrophoresis after reaction with a proteinase or methylamine. We find it difficult to envisage a mechanism by which the active site of the proteinase is essential for the initial interaction with $\alpha \mathrm{Mh}$, and in which the bound enzyme retains its catalytic activity though being sterically hindered, without implicating a conformational change in the $\alpha \mathrm{Mh}$, 

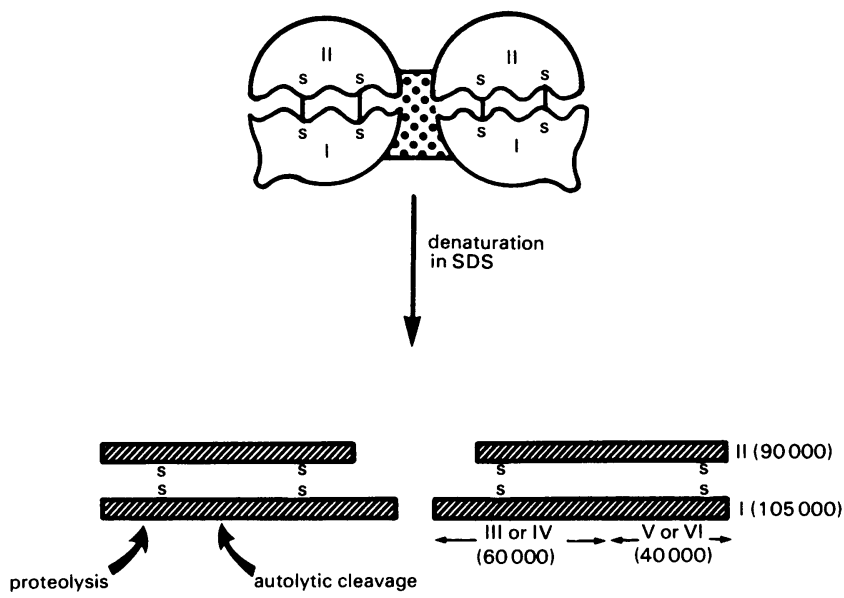

Fig. 8. Proposed subunit structure of plaice $\alpha M h$

The upper part of the Figure depicts the structure of the native protein. The actual number of disulphide bonds linking subunits I and II in heterologous dimers is unknown, but two only are shown for convenience. The non-covalent interactions linking the dimers in pairs are indicated by the stippled area, as it is not known whether these interactions occur between homologous subunits, heterologous subunits or both. In the lower part of the Figure, the subunits and fragments seen in SDS/polyacrylamide-gel electrophoresis of the denatured protein are depicted. These are drawn to scale, based on their $M_{\mathrm{r}}$ values as determined in SDS/polyacrylamide-gel electrophoresis ( $M_{\mathrm{r}}$ shown in parentheses), and the sites of specific proteinase cleavage and autolytic cleavage are indicated.

however. The selective clearance of $\alpha \mathrm{Mh}$-proteinase complexes from the circulation in vivo (Starkey et al., 1982) is also most easily explicable in terms of a conformational change.

On the basis of the model proposed for $\alpha \mathrm{Mh}$ in Fig. 8, there are two mechanisms by which the larger human $\alpha_{2} \mathrm{M}$ might have evolved from an ancestral protein similar to $\alpha \mathrm{Mh}$. The first requires that the structural genes for subunits I and II of $\alpha \mathrm{Mh}$ be adjacent and that a deletion of the 'stop sequence' between the two genes resulted in their being transcribed as a single mRNA, and translated as a single polypeptide chain corresponding to the quarter-subunit of $\alpha_{2} \mathrm{M}$. The second explanation requires that the $\alpha \mathrm{Mh}$ subunits be synthesized as a precursor of $M_{\mathrm{r}} 195000$ that is then post-translationally cleaved by a specific proteinase to give the separate I and II subunits. A mutation that resulted in a change in the amino acid sequence recognized by this specific proteinase could then give a precursor protein that was not cleaved but persisted as the $182000-M_{\mathrm{r}}$ subunit of the human protein.

This second explanation seems the most probable, and receives support from recent work on the complement proteins $\mathrm{C} 3$ and $\mathrm{C} 4$. These, despite their different physiological role, share important properties with $\alpha_{2} \mathbf{M}$. Thus all three proteins undergo a conformational change as a result of specific proteolytic attack, all are inactivated by amines, all undergo an autolytic cleavage in denaturing conditions that is prevented by prior inactivation by methylamine, and all are capable of forming covalent links with other proteins (Porter \& Reid, 1979; Campbell et al., 1980; Howard et al., 1980; Janatova \& Tack, 1981; Salvesen et al., 1981; Sim \& Sim, 1981). Moreover, the same sequence of seven amino acids occurs around the reactive thiol ester bond in complement proteins $\mathrm{C} 3$ and $\mathrm{C} 4$ and $\alpha_{2} \mathrm{M}$, and additional sequence homologies have also been reported (Swenson \& Howard, 1979; Tack et al., 1980; Campbell et al., 1981). In the light of these results it was first suggested by $\operatorname{Sim} \& \operatorname{Sim}(1981)$ that $\alpha_{2} \mathrm{M}$ and complement proteins $\mathrm{C} 3$ and $\mathrm{C} 4 \mathrm{might}$ share a common evolutionary origin. Each complement protein is synthesized as a single-chain precursor of $M_{\mathrm{r}}$ about 200000 that is post-translationally cleaved to two chains in protein $\mathrm{C} 3$ and three in protein C4 (Brade et al., 1977; Gigli, 1978; Goldberger \& Colten, 1980). If the quarter-subunit of $\alpha_{2} \mathbf{M}$ is aligned with the precursor forms of complement proteins $\mathrm{C} 3$ and $\mathrm{C} 4$ as shown in Fig. 9, it can be seen that in all three the site of specific proteolytic cleavage is roughly half way and the autolytic site two-thirds of the way from the $N$-terminus. By making assumptions for plaice $\alpha \mathrm{Mh}$ about which end of subunit I is the $N$-terminus, it is possible to align the $\alpha \mathrm{Mh}$ subunits as on a putative precursor molecule to fit the same pattern. 

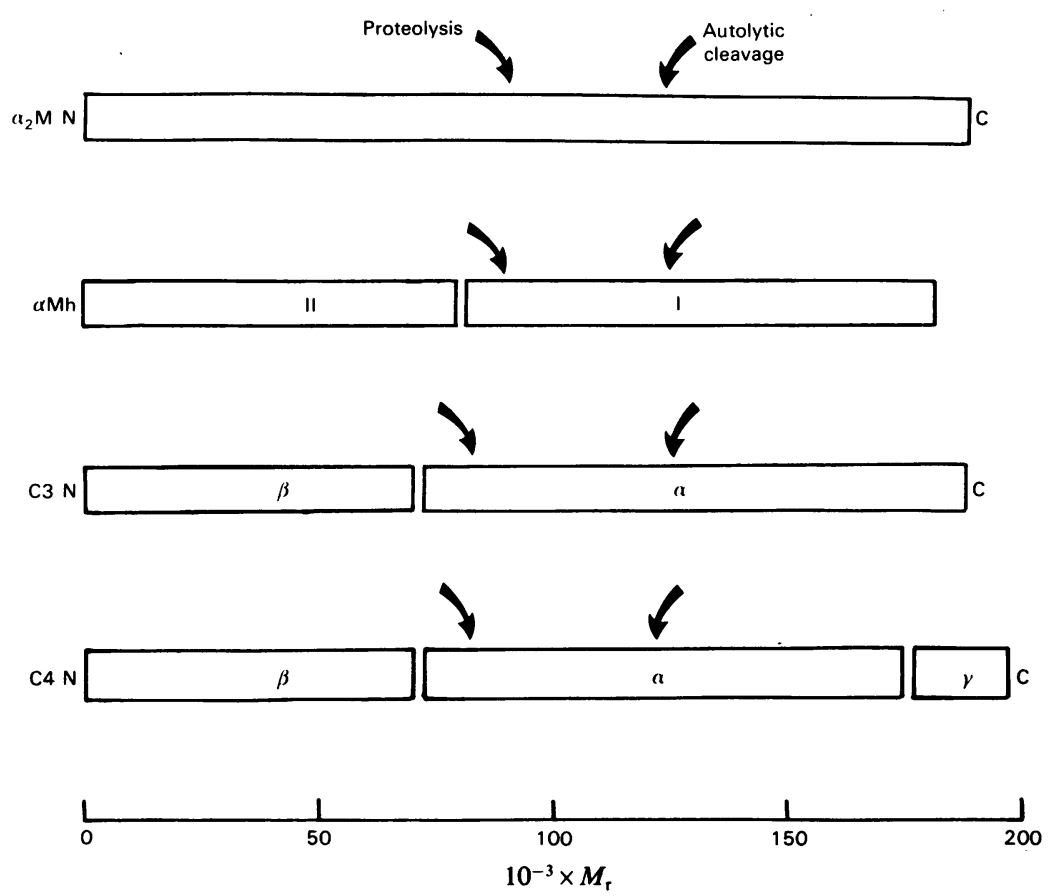

Fig. 9. Comparison of the subunits of human $\alpha_{2} M$, plaice $\alpha M$ and human complement components $C 3$ and $C 4$ This Figure, based on the scheme given by Sim \& Sim (1981) with the addition of the $\alpha \mathrm{Mh}$ data, depicts the quarter-subunit of human $\alpha_{2} \mathbf{M}$, and the polypeptide chains of plaice $\alpha \mathrm{Mh}$ and human complement proteins $\mathrm{C3}$ and C4 drawn to scale on the basis of the $M_{\mathrm{r}}$ values indicated by SDS/polyacrylamide-gel electrophoresis. The polypeptide chains of proteins $\mathrm{C} 3$ and $\mathrm{C} 4$ are aligned as they occur in the single-chain precursor molecules, and they and the quarter-subunit of $\alpha_{2} \mathrm{M}$ are orientated with the $N$-terminus at the left. The orientation and order of the $\alpha \mathrm{Mh}$ subunits in its putative precursor molecule are speculative. The positions of the sites of specific proteolytic cleavage and autolytic cleavage on each molecule are indicated by arrows.

We therefore propose that the larger $\alpha_{2} \mathrm{M}$ quartersubunit arose from the two $\alpha \mathrm{Mh}$ subunits by loss of the post-translational cleavage site, this mutation probably occurring in an early tetrapod (Starkey \& Barrett, 1982). It is likely that the mutation to the larger single type of subunit made possible new subunit interactions that led to the formation of the tetrameric $725000-M_{\mathrm{r}}$ molecule in place of the smaller fish molecule. However, in the absence of any structural studies on the macroglobulins of species other than mammals and actinopterygians, it cannot be ruled out that the changes in subunit size and molecular size occurred at different stages of evolution. The increased subunit interactions possible in the larger $\alpha_{2} \mathrm{M}$ may well have facilitated the conformational change on reaction with a proteinase and thus contributed to the apparently greater efficiency of the human protein compared with plaice $\mathrm{aMh}$ in trapping proteinases (Starkey et al., 1982).

It is known that elasmobranchs and actinoptery- gians contain amine-sensitive complement components that are presumably homologues of proteins C3 and/or C4 (Gigli \& Austen, 1971), and Nonaka et al. $(1981 a, b)$ have reported the isolation from rainbow-trout plasma of homologues of proteins $\mathrm{C3}$ and $\mathrm{C} 5$. In view of their apparent common evolutionary origin, it would clearly be of great interest to compare the structure of $\alpha \mathrm{Mh}$ and of homologues of proteins $\mathrm{C} 3$ or $\mathrm{C} 4$ in elasmobranchs or in the most primitive living vertebrates, the cyclostomes.

\section{References}

Barrett, A. J. \& Starkey, P. M. (1973) Biochem. J. 133, 709-724

Barrett, A. J., Starkey, P. M. \& Munn, E. A. (1974) in Proteinase Inhibitors (Fritz, H., Tschesche, H., Green, L. J. \& Truscheit, E., eds.), pp. 574-580, SpringerVerlag, Berlin

Barrett, A. J., Brown, M. A. \& Sayers, C. A. (1979) Biochem. J. 181, 401-418 
Brade, V., Hall, R. E. \& Colten, H. R. (1977) J. Exp. Med. 146, 759-765

Campbell, R. D., Dodds, A. W. \& Porter, R. R. (1980) Biochem. J. 189, 67-80

Campbell, R. D., Gagnon, J. \& Porter, R. R. (1981) Biosci. Rep. 1, 423-429

Clamp, J. R. (1977) Biochem. Soc. Trans. 5, 1693-1695

Fraker, P. J. \& Speck, J. C. (1978) Biochem. Biophys. Res. Commun. 80, 849-857

Gigli, I. (1978) Nature (London) 272, 836-837

Gigli, I. \& Austen, K. F. (1971) Annu. Rev. Microbiol. 25, 309-332

Goldberger, G. \& Colten, H. R. (1980) Nature (London) 286, 514-516

Harpel, P. C., Hayes, M. B. \& Hugli, T. E. (1979) J. Biol. Chem. 254, 8669-8678

Howard, J. B., Vermeulen, M. \& Swenson, R. P. (1980) J. Biol. Chem. 255, 3820-3823

Janatova, J. \& Tack, B. F. (1981) Biochemistry 20, 2394-2402

Lowry, O. H., Rosebrough, N. J., Farr, A. L. \& Randall, R. J. (1951) J. Biol. Chem. 193, 265-275

Nonaka, M., Yamaguchi, N., Natsuume-Sakai, S. \& Takahashi, M. (1981a) J. Immunol. 126, 1489-1494
Nonaka, M., Natsuume-Sakai, S. \& Takahashi, M. (1981b) J. Immunol. 126, 1495-1498

Porter, R. R. \& Reid, K. B. M. (1979) Adv. Protein Chem. 33, 1-71

Salvesen, G. S. \& Barrett, A. J. (1980) Biochem. J. 187, 695-701

Salvesen, G. S., Sayers, C. A. \& Barrett, A. J. (1981) Biochem. J. 195, 453-461

Sim, R. B. \& Sim, E. (1981) Biochem. J. 193, 129-141

Starkey, P. M. \& Barrett, A. J. (1977) in Proteinases in Mammalian Cells and Tissues (Barrett, A. J., ed.), pp. 663-696, North-Holland, Amsterdam

Starkey, P. M. \& Barrett, A. J. (1982) Biochem. J. 205, 91-95

Starkey, P. M., Fletcher, T. C. \& Barrett, A. J. (1982) Biochem. J. 205, 97-104

Swenson, R. P. \& Howard, J. B. (1979) Proc. Natl. Acad. Sci. U.S.A. 76, 4313-4316

Tack, B. F., Harrison, R. A., Janatova, J., Thomas, M. L. \& Prahl, J. W. (1980) Proc. Natl. Acad. Sci. U.S.A. 77, 5764-5768

Zacharius, R. M., Zell, T. E., Morrison, J. H. \& Woodlock, J. J. (1969) Anal. Biochem. 30, 148152 